\title{
A STUDY ON REPAIRING INTERNAL DEFECTS INSIDE CONCRETE USING THE ELECTROCHEMICAL DEPOSITION METHOD
}

Weichung Yeih

Department of Harbor and River Engineering, National Taiwan Ocean University, Keelung, Taiwan, R.O.C, wcyeih@mail.ntou.edu.tw

Hui-Mi Hsu

Department of Civil Engineering, National Ilan University, Ilan, Taiwan, R.O.C

Jiang-Jhy Chang

Department of Harbor and River Engineering, National Taiwan Ocean University, Keelung, Taiwan, R.O.C

Chi-Che Hung

Department of Harbor and River Engineering, National Taiwan Ocean University, Keelung, Taiwan, R.O.C

Rang Huang

Department of Harbor and River Engineering, National Taiwan Ocean University, Keelung, Taiwan, R.O.C

Follow this and additional works at: https://jmstt.ntou.edu.tw/journal

Part of the Civil and Environmental Engineering Commons

\section{Recommended Citation}

Yeih, Weichung; Hsu, Hui-Mi; Chang, Jiang-Jhy; Hung, Chi-Che; and Huang, Rang (2010) "A STUDY ON REPAIRING INTERNAL DEFECTS INSIDE CONCRETE USING THE ELECTROCHEMICAL DEPOSITION METHOD," Journal of Marine Science and Technology. Vol. 18: Iss. 3, Article 13.

DOI: $10.51400 / 2709-6998.1889$

Available at: https://jmstt.ntou.edu.tw/journal/vol18/iss3/13

This Research Article is brought to you for free and open access by Journal of Marine Science and Technology. It has been accepted for inclusion in Journal of Marine Science and Technology by an authorized editor of Journal of Marine Science and Technology. 


\title{
A STUDY ON REPAIRING INTERNAL DEFECTS INSIDE CONCRETE USING THE ELECTROCHEMICAL DEPOSITION METHOD
}

\author{
Weichung Yeih*, Hui-Mi Hsu**, Jiang-Jhy Chang*, Chi-Che Hung*, and Rang Huang*
}

Key words: electrochemical deposition, internal defects, concrete, air entrance agent.

\begin{abstract}
In this paper, the feasibility of repairing internal defects inside concrete using the electrochemical deposition method is investigated. Various amounts of the air entrance agent (AEA) were added into fresh concrete to produce small air bubbles. Zinc sulfate was used as the electrolyte for the electrochemical deposition method. The dry unit-weight test, compressive strength test, splitting tensile strength test, four-probe electric resistivity, water absorption percentage test, open circuit potential test, scanning electronic microscope (SEM) and X-ray diffraction are carried out to investigate the repair results. Results show that the electrochemical deposition method is a promising rehabilitation method when internal defects are required to be repaired.
\end{abstract}

\section{INTRODUCTION}

Reinforced concrete is a popular construction material worldwide. Although developments in material technology make concrete's life longer nowadays, reinforced concrete structures still deteriorate by physical and chemical attacks [3]. In such a manner, rehabilitation of reinforced concrete structures is a very important issue. Up to date, many repairing methods have been developed such as grouting [1, 10], epoxy injection [4], polymer injection and crystalline water proof agent [2] and electrochemical deposition method [12, 9]. Among them, most methods are used to repair concrete cracks when cracks have been reached surface. Crystalline waterproof agent has been added inside the fresh concrete such that internal defects can be repaired automatically. However, for a mature concrete with internal defects crystalline water proof

Paper submitted 05/15/09; accepted 07/10/09. Author for correspondence: Weichung Yeih (e-mail: wcyeih@mail.ntou.edu.tw).

*Department of Harbor and River Engineering, National Taiwan Ocean University, Keelung, Taiwan, R.O.C.

**Department of Civil Engineering, National Ilan University, Ilan, Taiwan, R.O.C. agent cannot effectively repair it since no natural route for the crystalline water proof agent to permeate into concrete. Although the connected pores inside concrete may provide a route for permeation of the crystalline water proof agent, the time duration may be too long since the permeation rate mainly depends on the pore structures and finer pores requires longer time to permeate through. Electrochemical deposition method adopts DC power to force metal ions with +2 valence to migrate into concrete and deposition pile up inside the defects (voids, pores and cracks). In previous studies [12, 9], electrochemical deposition method has been proved to be an effective method to repair concrete cracks, which have reached concrete surface. However, the feasibility of the electrochemical deposition method to repair internal defects has not been investigated to authors' best knowledge. In the followings, the methodology of the electrochemical deposition method is briefly introduced.

The rebar is used as the cathode and connected to the DC power supply and the titanium mesh is used as the anode. Many choices can be made for the electrolyte [6] and $\mathrm{ZnSO}_{4}$ solution has the best performance as reported in [5], but later they have reported that $\mathrm{MgCl}_{2}$ solution is better [8]. As the polarization process continues, the electrochemical deposition seals the cracks. This deposition forms a physical barrier to prevent the further penetration of hazard species [7]. Since the applied cathodic current density is so low such that the possibility of the accelerating alkali-silica aggregate reaction due to the cathodic current is very low. The typical chemical reactions for using $\mathrm{ZnSO}_{4}$ solution as the electrolyte are listed as follows [7].

The anodic reaction is

$$
2 \mathrm{H}_{2} \mathrm{O} \rightarrow \mathrm{O}_{2} \uparrow+4 \mathrm{H}^{+}+4 \mathrm{e}^{-}
$$

and the cathodic reaction is

$$
2 \mathrm{H}_{2} \mathrm{O}+2 \mathrm{e}^{-} \rightarrow 2 \mathrm{OH}^{-}+\mathrm{H}_{2} \uparrow
$$

The reaction in the electrolyte for $\mathrm{ZnSO}_{4}$ solution is

$$
\mathrm{ZnSO}_{4} \rightarrow \mathrm{Zn}^{2+}+\mathrm{SO}_{4}^{2-}
$$


and the zinc ions move towards the rebar. The zinc ions react with the hydroxide ions as

$$
\mathrm{Zn}^{2+}+2 \mathrm{OH}^{-} \rightarrow \mathrm{ZnO} \downarrow+\mathrm{H}_{2} \mathrm{O}
$$

The electrochemical deposition condenses the pores inside the concrete, and the deposing rate is higher at the root of the crack. The typical setup for the electrochemical deposition is illustrated in Fig. 1.

Theoretically speaking, the electrochemical deposition piles up faster at the position with higher current density. It implies concrete defects such as voids, cracks and pores can be effectively repaired by the electrochemical deposition since the current density for liquid-filled defects is higher. In addition, the migration of ions is due to electrical field such that a faster repair process is expected than natural permeation process. Especially for internal defects such that no major permeation route reaching out of the concrete surface, the electrochemical deposition method may be a very good alternative. This article investigates the feasibility of electrochemical deposition method to repair internal defects inside concrete.

\section{EXPERIMENTAL}

Cylindrical concrete specimens with diameter of $10 \mathrm{~cm}$ and height of $20 \mathrm{~cm}$ were cast. The mix design of concrete specimens is tabulated in Table 1. Type I cement were used, and local coarse aggregates with fineness modulus (F.M.) of 6.43 were used. Natural river sands from China with fineness modulus of 2.65 were used as the fine aggregates. To make internal defects inside concrete, various amounts of air entrance agent (AEA) were added. The air entrance agent used was TRICOSAL ®LP SPECIAL made by GRUNAU company and it contains alkaline salts of abietinic acid. The ratios of AEA over cement (AEA/C ratio) were $0 \%, 0.025 \%, 0.05 \%$, $0.1 \%, 0.2 \%$ and $0.3 \%$. Since we added air entrance agent (AEA), it produced voids inside concrete such that the final volume will be larger than designed volume. It then is very nature to have a unit weight lower than the designated one while the volume now is larger than the designed volume. It is not easy to estimate how much volume increment using AEA since it depends on the dosage and the w/c ratio. In the center of concrete specimens, steel wires were placed to act as the cathodes. The specimens were demolded after one day then placed in the standard curing condition till 28 days.

After curing, all specimens were connected to DC power supply. The steel wire was connected to cathode and titanium mesh was connected to anode. Constant current density of 0.5 $\mathrm{A} / \mathrm{m}^{2}$ (with respect to the cathode surface area) was fed. The electrolyte used was $0.1 \mathrm{M}$ zinc sulfate solution, which was made from zinc-sulfate-7-hydrate powders.

After repair process continued for 14, 28, 42 and 56 days, several tests were carried out to see whether the electrochemical deposition can repair internal defects. The following tests were carried out:

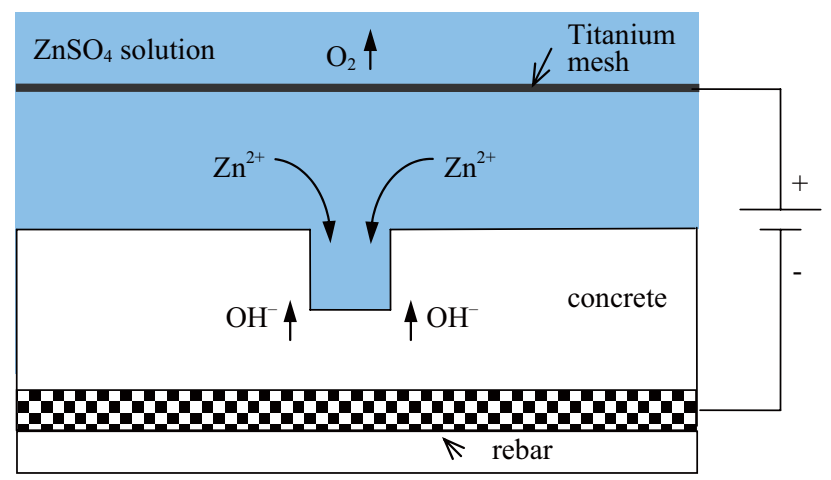

Fig. 1. Illustration for the setup of electrochemical deposition method.

Table 1. Mix designs for concrete specimens.

\begin{tabular}{ccccc}
\hline $\begin{array}{c}\text { Water/Cement } \\
\text { ratio }\end{array}$ & $\begin{array}{c}\text { Water } \\
\left(\mathrm{kg} / \mathrm{m}^{3}\right)\end{array}$ & $\begin{array}{c}\text { Cement } \\
\left(\mathrm{kg} / \mathrm{m}^{3}\right)\end{array}$ & $\begin{array}{c}\text { Fine } \\
\text { aggregate } \\
\left(\mathrm{kg} / \mathrm{m}^{3}\right)\end{array}$ & $\begin{array}{c}\text { Coarse } \\
\text { aggregate } \\
\left(\mathrm{kg} / \mathrm{m}^{3}\right)\end{array}$ \\
\hline 0.7 & 212 & 303 & 658 & 1085 \\
\hline
\end{tabular}

\section{Indirect Evidences for Pore Structure Changes: Dry Unit Weight and Water Absorption}

If the electrochemical deposit exists in the concrete defects, the unit weight of concrete is expected to be increased. The specimens should be set to oven dry condition to avoid counting possible water weight. Water absorption test was also carried out to examine the pore structure changes. When the defects were condensed by deposits, the absorption capability of concrete will reduce.

\section{Mechanical Tests: Compressive Strength and Splitting Tensile Strength}

When the defects inside concrete are condensed by the deposit, the mechanical properties are expected to be enhanced. The compressive strength and splitting tensile test were carried out to examine the repair effects on improvement of mechanical properties. Though the steel wire was embedded in the concrete to act as the electrode, it would not influence the compressive strength and tensile strength much due to its small size. Since all specimens contain steel wire, the values can be compared relatively.

\section{Corrosion Prevention Capability: Open Circuit Potential and Four Probe Electrical Resistivity}

Durability of repaired concrete is examined by using the open circuit potential and four probe electrical resistivity. The open circuit potential indicates the thermodynamic trend of corrosion. When the open circuit potential is nobler, the risk of corrosion is lower. Four probe electrical resistivity was measured to see the resistivity of concrete. The resistivity relates to the pore water content such that to keep all specimens in the same condition is very important. In this study, the surface saturate dry (SSD) condition of concrete is used. It is 


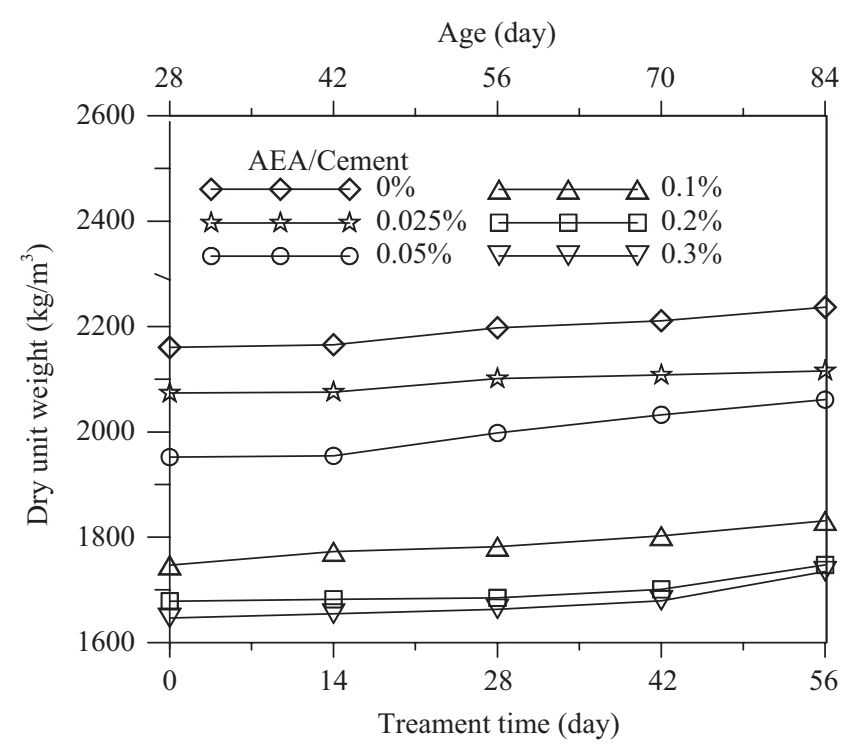

Fig. 2. Dry unit weights for repaired concrete specimens.

known that concrete with higher resistivty has a better corrosion prevention capability.

\section{Micro-Scale Evidences: Scanning Electronic Microscope and X-ray Diffraction}

Scanning electronic microscope was carried out to see the changes of pore structure in the micro-scale. X-ray Diffraction was used to examine the chemical elements for the deposit.

\section{RESULTS}

\section{Indirect Evidences for Pore Structure Changes: Dry Unit Weight and Water Absorption}

Test results for dry unit weight are illustrated in Fig. 2. As seen in the figure, dry unit weight of concrete increased as the rehabilitation process time increased. This indicates that deposits piled up inside concrete such that unit weight increased.

The water absorption percentage usually is thought to reflect the total connected pore and defect volume inside the concrete. In Fig. 3, it can be found that the water absorption percentage decreased as the rehabilitation process time increased. It once again implies that the deposits effectively piled up inside concrete. In addition, one can observe that concrete without adding any AEA showed the fastest decreasing rate in the water absorption after 28 day treatment. In comparison with concrete specimens adding with AEA, concrete without adding AEA did not contain many air bubbles such that electrochemical deposit quickly piled up within the concrete pores and later began to block connected routes, and consequently reduced the water absorption dramatically. From the indirect evidences shown above, we can conclude that concrete microstructure was for sure condensed.

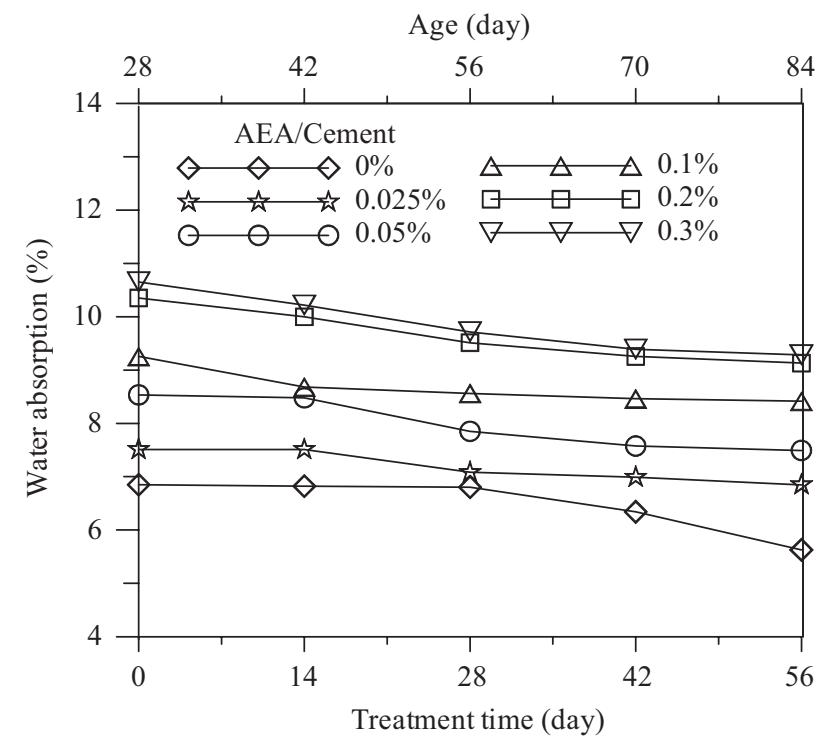

Fig. 3. Water absorption percentages for repaired concrete specimens.

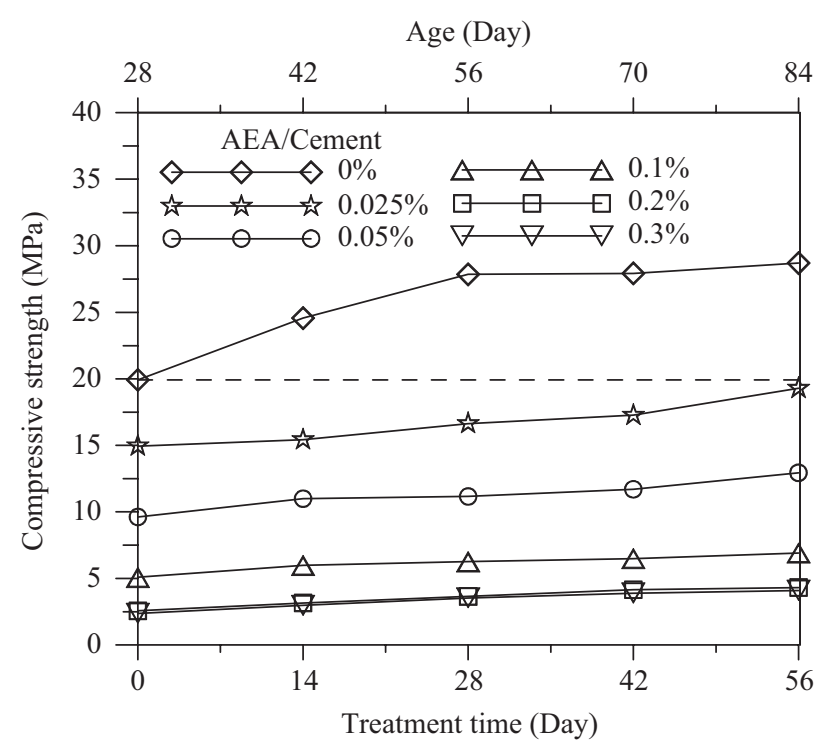

Fig. 4. Compressive strengths for repaired concrete specimens.

\section{Mechanical Tests: Compressive Strength and Splitting Tensile Strength}

The compressive strength is a very important index for concrete. Many designers relate concrete properties to the compressive strength. In such a manner, concrete with higher compressive strength is thought as a better material. As shown in Fig. 4, compressive strength of concrete increased as the rehabilitation time increased. For concrete without adding AEA, compressive strength reached almost $28 \mathrm{MPa}$ after 28-day treatment and not much more increment in concrete compressive strength was found. It seems that the effect of repair has its limitation. This is because of that the electrochemical deposit although can condense the microstructure 


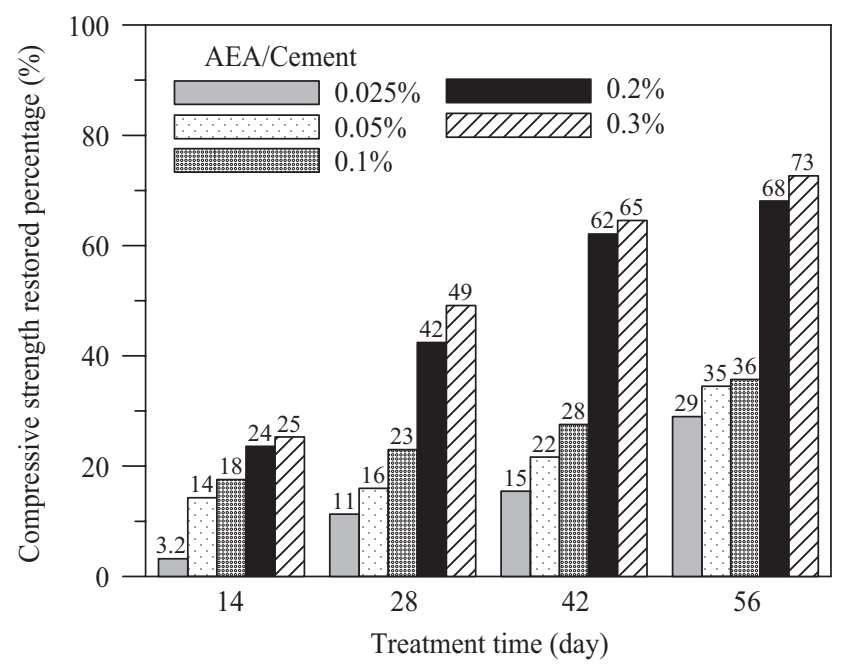

Fig. 5. Compressive strength restored percentages.

and consequently increase the compressive strength, it also block the route for ion penetration. Therefore, as treatment continues the ions penetration becomes harder. This phenomenon is found whenever the cathodic current is applied to rebar, e.g., the electrochemical chloride removal [11]. In addition, it can be found that after 56-day treatment the compressive strength for concrete adding $0.025 \% \mathrm{AEA} / \mathrm{C}$ ratio reached the 28-day compressive strength of the control specimen (without AEA), the value represented by the dashed line in the figure.

If for each concrete group one defines the original 28-day compressive strength as $f_{C}^{\prime}$ and denotes the compressive strength after k-day electrochemical treatment as $f_{k}$, then the compressive strength retrofitting percentage for k-day electrochemical treatment, $\beta_{k}$, is defined as

$$
\beta_{k} \equiv \frac{f_{k}-f_{C}^{\prime}}{f^{\prime}} \times 100 \%
$$

In Fig. 5, it can be seen that concrete compressive strength retrofitting percentage increased as the treatment time increased. For concrete adding with $0.3 \%$ AEA, after 56-day treatment the compressive strength increased over $70 \%$ in comparison with 28-day compressive strength (no repair).

In Fig. 6, the splitting tensile strength for concrete is illustrated. It can be found that splitting tensile strength increased as the treatment time increased. In addition, after 42-day treatment the splitting tensile strength of concrete with $0.025 \%$ $\mathrm{AEA} / \mathrm{C}$ ratio exceeded 28-day splitting tensile strength of the control specimen.

The above mentioned results indicate that electrochemical deposit method increased mechanical strength for concrete.

\section{Corrosion Prevention Capability: Open Circuit Potential and Four Probe Electrical Resistivity}

In Table 2, the open circuit potentials are tabulated. Ac-

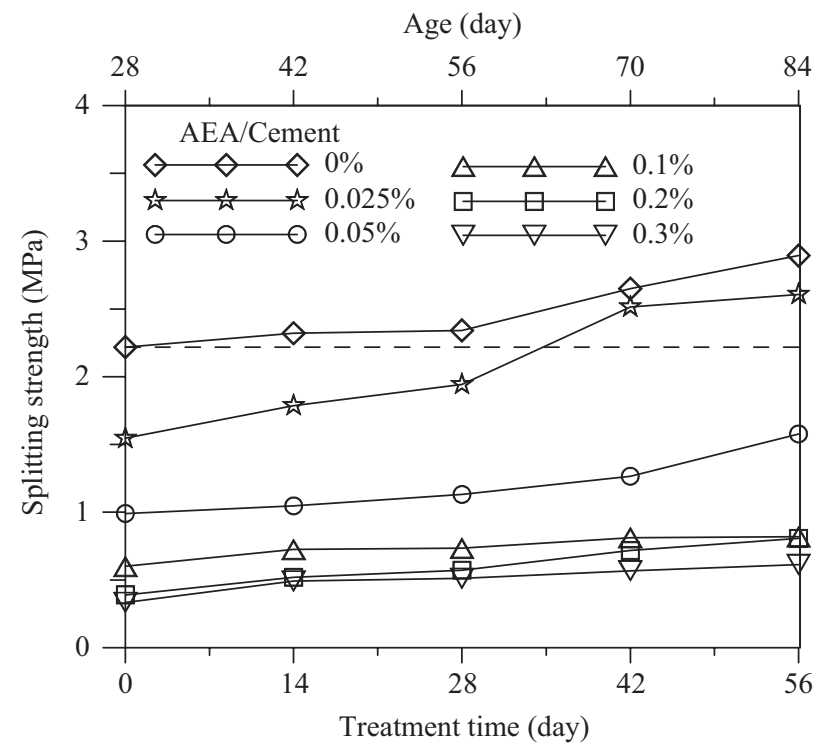

Fig. 6. Splitting tensile strengths for repaired concrete specimens.

Table 2. Open circuit potentials (mV/SCE) for concrete specimens after repair.

\begin{tabular}{crrrrrc}
\hline Treatment & \multicolumn{7}{c}{ AEA/C $(\%)$} \\
\cline { 2 - 7 } time (days) & \multicolumn{1}{c}{0} & 0.025 & 0.05 & 0.1 & 0.2 & 0.3 \\
\hline 0 & -146 & -151 & -153 & -160 & -165 & -173 \\
14 & -97 & -101 & -102 & -104 & -114 & -138 \\
28 & -88 & -98 & -100 & -101 & -111 & -131 \\
42 & -77 & -82 & -87 & -96 & -102 & -111 \\
56 & -69 & -74 & -76 & -85 & -94 & -111 \\
\hline
\end{tabular}

cording to ASTM C876-91, the corrosion possibility for steel embedded in concrete is lower than $10 \%$ when the open circuit potential is higher than $-120 \mathrm{mV}(\mathrm{SCE})$ and is higher than $90 \%$ when the open circuit potential is lower than $-270 \mathrm{mV}$ (SCE). From the table, it can be seen for all concrete specimen groups the open circuit potential became nobler than -120 mV(SCE) after 56-day treatment. In addition, the open circuit potential all tended to the nobler potential when the treatment time increased. It means that embedded steel become less likely corroded.

In Fig. 7, the four-probe electrical resistivity values are illustrated. As the treatment time increased, the resistivity became higher. It is known that when the resistivity of concrete becomes higher the corrosion prevention capability of concrete is enhanced as well. From the above mentioned results, we can claim that the corrosion prevention capability of concrete is improved after electrochemical deposition repair.

\section{Micro-Scale Evidences: Scanning Electronic Microscope and X-ray Diffraction}

Above mentioned results all indicates that concrete microstructures are improved by the deposit. To obtain the micro- 


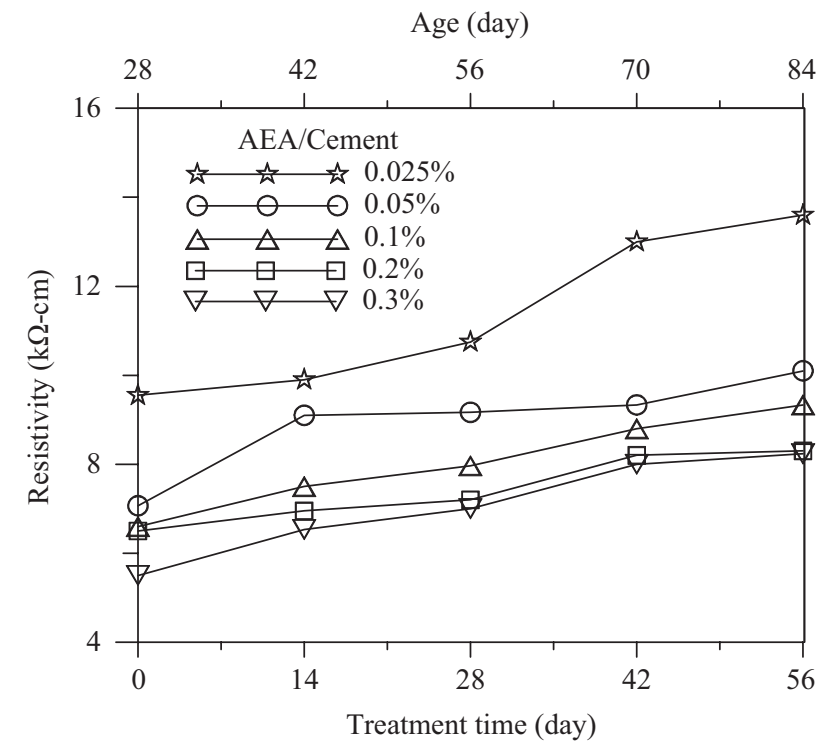

Fig. 7. Four-probe electrical resistivity values for repaired concrete specimens.

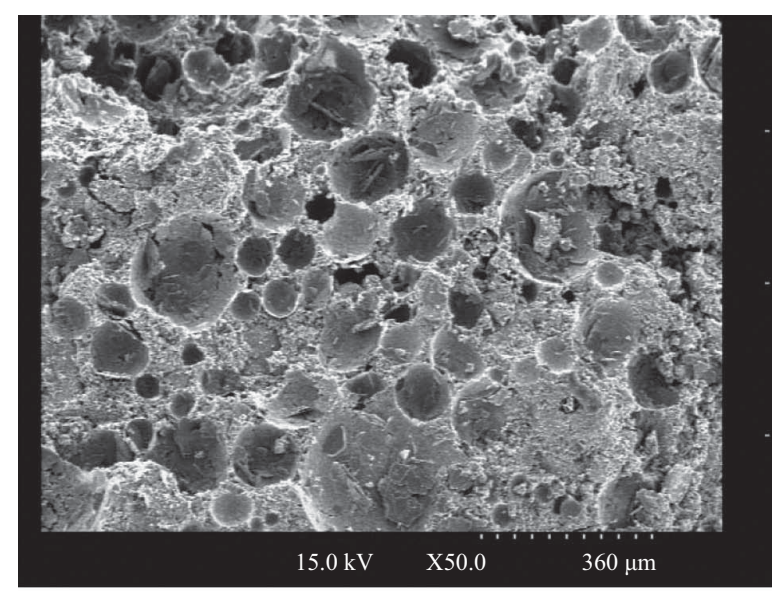

(a)

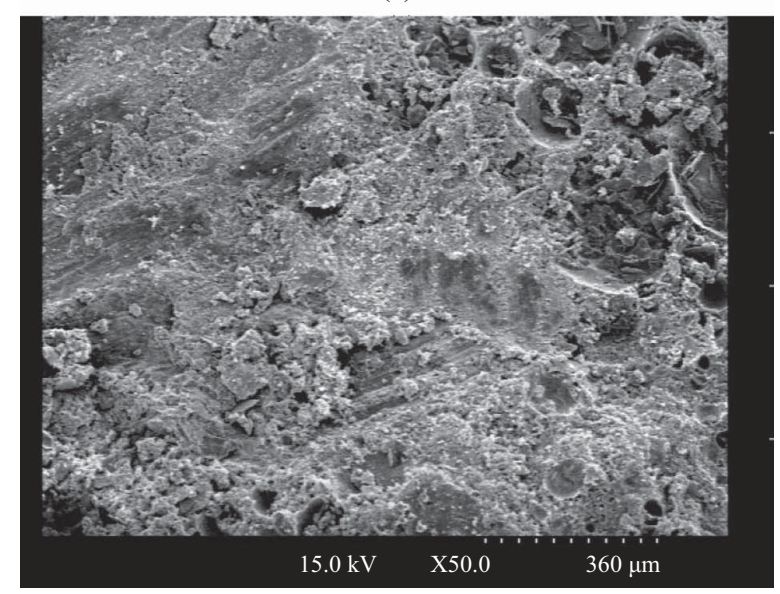

(b)

Fig. 8. Scanning electronic microscope photos (X50) for concrete specimens with $\mathrm{AEA} / \mathrm{C}=0.1 \%$ : (a) before repair; (b) after 8-week treatment.

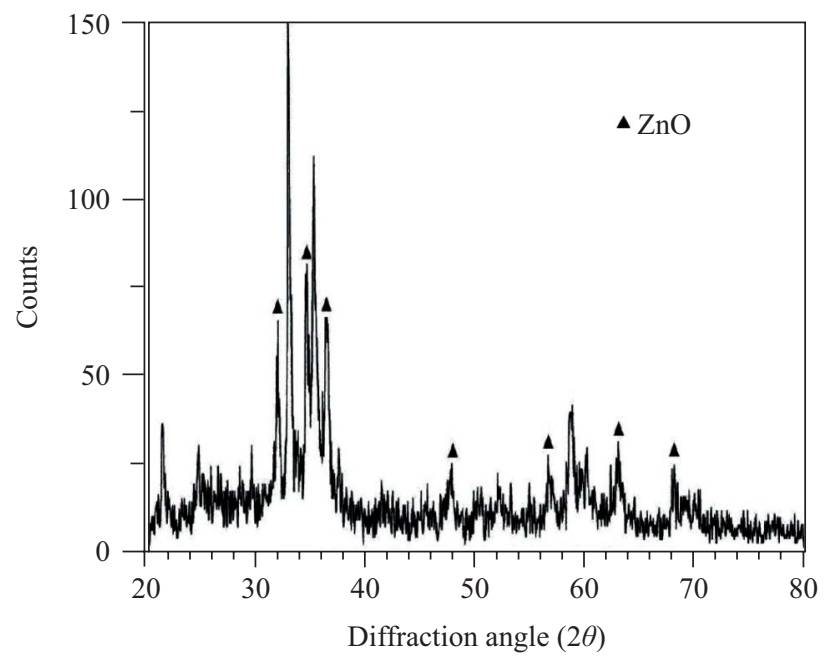

Fig. 9. X-ray diffraction results for the deposit.

scale evidences, the scanning electronic microscope (SEM) photos were taken. In Fig. 8, the microstructure photos for concrete groups with $0.1 \% \mathrm{AEA} / \mathrm{C}$ ratio before repair and after 8 -week treatment are compared. It can be easily figured out that voids existed widely before repair and they were apparently repaired by deposit after treatment.

To understand more about the deposit inside the concrete, the X-ray diffraction test was carried out. In Fig. 9, it can be seen that many peaks corresponding to $\mathrm{ZnO}$ were found. It reconfirmed the result mentioned in the existing literature [5].

\section{CONCLUSIONS}

In this paper, the feasibility of using electrochemical deposit method to repair defects inside concrete is investigated. Results shows that the electrochemical deposit method can effectively repair internal concrete defects, increase concrete mechanical properties and improve corrosion prevention capability. Corrosion resistance can be improved by electrochemical method in this work. The cathodic reaction produces hydroxyl ion $\left(\mathrm{OH}^{-}\right)$and then passivates the rebar. Open circuit potential is increased with charging time. All these evidences imply that the current method improves the corrosion resistance of concrete. Scanning electronic microscope photos show the voids are effectively condensed by the deposit and the chemical composition of deposit is $\mathrm{ZnO}$ by the result of $\mathrm{X}$-ray diffraction method.

The electrochemical deposition method is a very interesting retrofitting method especially for repairing internal defects. To understand more about this method, more studies are required.

\section{REFERENCES}

1. Chong, G. J., Rout and Seal Cracks in Flexible Pavement: A CostEffective Maintenance Procedure, Report PAV-89-04, Ontario Ministry of Transportation, Aug. (1989). 
2. Florian, K., "Crystalline waterproofing at hydro-electric power plant," Concrete Engineering, Vol. 11, pp. 30-40 (2007).

3. Mehta, P. K., Concrete in The Marine Environment, Elsevier Applied Science, New York (1991).

4. Moetaz, E. H., Husain, A. K., and Sami, F., "Performance of epoxy-repaired concrete in a marine environment," Cement and Concrete Research, Vol. 30, No. 2, pp. 259-266 (2000).

5. Otsuki, N. and Ryou, J. S., "Use of electrodeposition for the repair of concrete with shrinkage cracks," Journal of Materials in Civil Engineering (ASCE), Vol. 13, No. 2, pp. 136-142 (2001).

6. Ryou, J. S. and Otsuki, N., "Crack block and surface improvement of electrodeposition," Proceedings of the Annual Conference of Japanese Society of Civil Engineers, pp. 270-271 (1998).

7. Ryou, J. S. and Otsuki, N., "Crack closure of reinforced concrete by electrodeposition technique," Cement and Concrete Research, Vol. 32, No. 1, pp. 159-164 (2002).
8. Ryou, J. S. and Otsuki, N., "Experimental study on repair of concrete structural members by electrochemical method," Scripta Materialia, Vol. 52, pp. 1123-1127 (2005).

9. Sasaki, H. and Yokoda, M., "Repaired method of marine reinforced concrete by electrodeposition technique," Proceedings of the Annual Conference of Japanese Concrete Institute, pp. 849-854 (1992).

10. Shannag, M. J., "High-performance cementitious grouts for structural repair," Cement and Concrete Research, Vol. 32, No. 5, pp. 803-808 (2002).

11. Yeih, W., Chang, J. J., and Hung, C. C., "Selecting an Adequate Procedure for the Electrochemical Chloride Removal," Cement and Concrete Research, Vol. 36, No. 3, pp. 562-570 (2006).

12. Yokoda, M. and Fukute, T., "Rehabilitation and protection of marine concrete structure using electrodeposition method," Proceedings of the International RILEM/CSIRO/ACRA Conference on Rehabilitation of Concrete Structures, RILEM, Melbourne, pp. 213-222 (1992). 